\title{
The Differentiation Responses of Dictyostelium discoideum Amoebae at Various Times During Synchronous Growth
}

\author{
By CLIVE WOFFENDIN AND ALAN J. GRIFFITHS* \\ Microbiology Department, University College, Newport Road, Cardiff CFI IXP, U.K.
}

(Received 1 December 1981; revised 25 January 1982)

\begin{abstract}
Synchronous cultures of the cellular slime mould, Dictyostelium discoideum, were prepared by a selection method which involved low-speed centrifugation of exponential cultures. The method gave a relatively high degree of synchronous growth and cell doubling and a discrete phase of DNA synthesis was discernible. Amoebae which were induced to sporulation at different times during synchronous growth differed in their differentiation responses. Those which were about to divide produced more fruiting bodies and had higher levels of $\alpha$-mannosidase and $N$-acetylglucosaminidase than cells removed to sporulation conditions at other times during synchronous growth.
\end{abstract}

\section{INTRODUCTION}

The physiological and biochemical changes which accompany sporulation of the cellular slime mould Dictyostelium discoideum have been extensively studied and reviewed (Loomis, 1975). Although it is also well known that many similar qualitative and quantitative changes occur during the growth-division cycle of other eukaryotic microbes (Mitchison, 1971), the growth of $D$. discoideum has received little attention. The study of growth has been facilitated by the isolation of axenic strains (Sussman \& Sussman, 1967; Watts \& Ashworth, 1970; Ashworth \& Watts, 1970; Loomis, 1971) which also exhibit normal sporulation. Exponential growth of the axenic strain Ax-2 has been described (Watts \& Ashworth, 1970; Ashworth \& Watts, 1970) but studies of the cell cycle have been based either on induced synchrony of temperature-sensitive mutants (Katz \& Bourguignon, 1974) or of 'stationary phase' cells, which when transferred to fresh growth medium, divide synchronously (Zada-Hames \& Ashworth, 1978). In this paper we describe a method for obtaining synchronous cultures of $D$. discoideum which is based on a selection principle, and investigate the differentiation competence of the cells at various times during synchronous growth.

\section{METHODS}

Organism and growth conditions. Dictyostelium discoideum Ax-2 strain, was kindly provided by S. Minter, Essex University, U.K. Amoebae were grown on the medium described by Watts \& Ashworth (1970) except that Difco yeast extract was substituted for the Oxoid product. Cultures were grown in $50 \mathrm{ml}$ medium in a $250 \mathrm{ml}$ conical flask, or in $100 \mathrm{ml}$ medium in a $500 \mathrm{ml}$ flask. All cultures, whether exponential or synchronous, were incubated at $22{ }^{\circ} \mathrm{C}$ on a reciprocal shaker at $80 \mathrm{rev} . \mathrm{min}^{-1}$.

Preparation of synchronous cultures. Synchronous cultures were prepared by a modification of the low-speed centrifugation method described by Chagla \& Griffiths (1978). Exponential cultures were first centrifuged in sterile, stoppered centrifuge tubes $(50 \mathrm{ml})$ at $570 \mathrm{rev} \cdot \min ^{-1}\left(35 \mathrm{~g}, r_{\mathrm{av}}=10 \mathrm{~cm}\right)$ for $2 \mathrm{~min}$ in an MSE bench centrifuge. The supernatant appeared to contain a high proportion of non-viable cells and was discarded. The cell pellet was resuspended in sufficient conditioned growth medium (prepared by centrifuging another exponential culture of the same age so that it was completely free of cells) to restore the original culture volume. The reconstituted culture was again centrifuged at $500 \mathrm{rev} \cdot \mathrm{min}^{-1}$ and the resulting supernatant, which contained about $10 \%$ of the cells which were present in the original exponential culture, was decanted carefully into a clean, sterile conical flask and constituted the synchronous culture. The degree of synchrony was estimated by the synchrony index $(F)$ of Blumenthal \& Zahler (1962) which has a value of 1.00 for a perfectly synchronous culture. 
Cell counts. Amoebae were counted without prior fixation in a Fuchs-Rosenthal haemocytometer (Weber \& Sons, Lancing, Sussex, U.K.). A minimum of 200 cells were counted for each sample.

Measurement of DNA. Samples (2-5 ml) were washed twice with distilled water and sonicated for $10 \mathrm{~s}$ at $40 \mathrm{~W}$. Trichloracetic acid $(5 \%, \mathrm{w} / \mathrm{v}$ final concentration) was then added to the samples and DNA was extracted using the procedures described by Herbert et al. (1971). DNA was measured by a fluorimetric method (Kissane \& Robins, 1955), with Sigma calf thymus DNA (type IIs, sodium salt) as the standard.

Induction of differentiation. Amoebae were collected by centrifugation and washed with water. Development was initiated by transferring washed cell suspensions to (i) Millipore filters (AABP047) supported on absorbent pads which were soaked either with a solution containing $50 \mathrm{~mm}$-phosphate buffer (pH 6.4), $\mathrm{KCl}\left(1.5 \mathrm{mg} \mathrm{ml}^{-1}\right)$ and $\mathrm{MgCl}_{2}\left(0.5 \mathrm{mg} \mathrm{ml}^{-1}\right)$ or with water alone, and (ii) $2 \%(\mathrm{w} / \mathrm{v})$ non-nutrient agar plates. For both methods incubation was at $22^{\circ} \mathrm{C}$.

Cell suspensions were spread over a fixed area of agar or Millipore filter so that the number of cells per unit area was the same. The number of fruiting bodies formed after $48 \mathrm{~h}$ incubation on agar was estimated by examining known areas $\left(75 \mathrm{~mm}^{2}\right)$ using a template. Eight to twelve areas were examined for each sample and at least 400 fruiting bodies were counted. All the fruiting bodies $(450-1500)$ which had formed on Millipore filters were counted. Each sample was duplicated and the averages of the two estimates were expressed as a percentage of the highest values obtained.

Measurement of enzyme activities during development. After $4 \mathrm{~h}$ development on membrane filters, samples were taken by scraping off the cells into $3 \mathrm{ml}$ distilled water. These samples were then frozen until required when they were thawed and sonicated for $10 \mathrm{~s}$ at $20 \mathrm{kHz}, 500 \mathrm{~W}$ in an MSE sonicator. The levels of $\alpha$-mannosidase were measured by the method described by Loomis (1970), with $5 \mathrm{mM}-p$-nitrophenyl- $\alpha$-mannoside as the substrate. $N$-Acetylglucosaminidase was measured with $8 \mathrm{~mm}$ - $p$-nitrophenyl- $N$-acetylglucosamine as the substrate (Loomis, 1969). In both cases, one unit of enzyme is that amount which liberates $1 \mathrm{nmol}$ nitrophenol $\mathrm{min}^{-1}$.

\section{RESULTS AND DISCUSSION}

The change in numbers of $D$. discoideum amoebae after the low-speed centrifugation procedure is shown in Fig. 1. Two cycles of cell division were followed and these gave synchrony indices $(F)$ of 0.72 for the first cycle and 0.46 for the second cycle. In the first cycle, division occupied $1.9 \mathrm{~h}$ and the ratio of cell numbers after and before division $\left(N / N_{0}\right)$ was 1.98 ; in the second cycle these values were $1.0 \mathrm{~h}$ and 1.65 , respectively. In 14 experiments synchrony indices for the first cycle ranged from 0.6 to 0.78 (mean 0.70 , S.D. 0.06 ) and $N / N_{0}$ ratios ranged from 1.83 to 1.98 (mean 1.90, S.D. 0.05). Division times varied from 1.25 to $2.25 \mathrm{~h}$ (mean $1 \cdot 81$, S.D. 0.34 ). There was some variation in the lag before the cells divided [1.25-2.4 h (mean 1.91, S.D. 0.30)] and the cell cycle times, measured as the time between the start of successive divisions, varied from 5.5 to $6.0 \mathrm{~h}$. There was a sharp increase in the DNA content of the cells during the growth of the synchronous cultures (Fig. 2).

Cells taken at different times from the synchronous cultures, and induced to differentiate by transfer to agar plates and Millipore filters, differed in their sporulation responses and in their levels of $\alpha$-mannosidase and $N$-acetylglucosaminidase. Amoebae which were induced to undergo development just prior to cell division gave the highest level of fruiting body formation. The lowest number of fruiting bodies was formed by amoebae removed from the synchronous cultures towards the end of the division phase.

The two enzymes which were measured in our experiments have been shown to increase rapidly during the initial stages of differentiation of $D$. discoideum (Loomis, 1969, 1970) and are therefore sensitive indicators of the differentiation responses of amoebae. There appears to be complete agreement in the rank order of the samples in relation to fruiting body formation and enzyme levels (Table 1).

Some important features of the selection method described here are that the degree of synchrony and the ratios of cell numbers before and after cell division were comparable with the values obtained with synchronous cultures of other eukaryotic microbes [which were also established by centrifugation (Lloyd et al., 1975; Chagla \& Griffiths, 1978)]. The procedure would seem, therefore, to be a suitable method for further studies of the growth of $D$. discoideum.

The cell cycle time of 5.5-6.0 h was shorter than that reported for exponential cultures of the Ax-2 strain (Zada-Hames \& Ashworth, 1978) and for temperature-induced synchronous cultures of the Ax-3 strain (Katz \& Bourguignon, 1974). The lengths of the DNA synthesis (S) phase and 


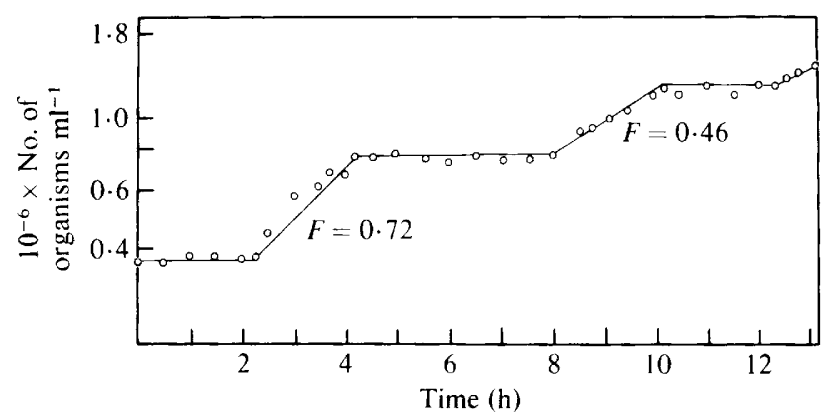

Fig. 1. Changes in cell number during synchronous growth of $D$. discoideum. The synchronous culture contained $13 \%$ of the original exponential culture. Cell numbers were estimated every $0.25 \mathrm{~h}$ in a haemocytometer. Synchrony indices $(F)$ for the first two cycles of cell division are shown.

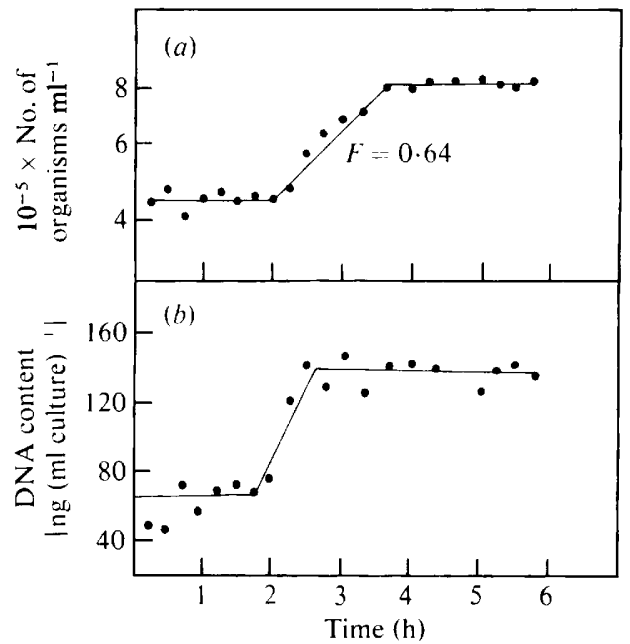

Fig. 2. Changes in cell number $(a)$ and DNA content $(b)$ of $D$. discoideum during synchronous growth. Cell suspensions $(2-5 \mathrm{ml})$ were washed and sonicated. DNA was extracted and measured fluorimetrically. ( $F$, synchrony index).

Table 1. Fruiting body formation and enzyme levels of developing cells taken at various times from synchronous cultures

Cells were taken at the times indicated during synchronous growth (shown in Fig. 2) and development initiated as described in Methods. After $48 \mathrm{~h}$, the number of fruiting bodies was estimated, and expressed as a percentage of the maximum value. The enzymes $\alpha$-mannosidase and $N$-acetylglucosaminidase were assayed after $4 \mathrm{~h}$ development; enzyme units are nmol nitrophenol released $\min ^{-1}$.

Time at which cells were removed from synchronous cultures $(\mathrm{h})$

$$
\begin{aligned}
& 0 \cdot 25-0.5 \\
& 1 \cdot 5-1 \cdot 6 \\
& 2 \cdot 9-3 \cdot 25 \\
& 4 \cdot 5-4 \cdot 65
\end{aligned}
$$

Fruiting bodies
formed
$(\%)$
85
100
55
58

Enzyme activity [units (mg protein) ${ }^{-1}$ ]

$\begin{array}{cc}\alpha \text {-Mannosidase } & N \text {-Acetylglucosaminidase } \\ 4.61 & 18.40 \\ 5.55 & 25 \cdot 80 \\ 1.42 & 9.20 \\ 3.52 & 17.20\end{array}$

the $G_{2}$ phase appeared to be shorter in our cultures than in previous estimates, although the $G_{1}$ phase was of about the same duration. The discrepancies between our results and those of previous workers concerning the length of the DNA synthesis phase could be due to the different methods which were used to measure DNA levels. Synchronous cultures do not, however, allow 
the various phases of the cell cycle to be delineated with absolute precision and the times reported here would need to be confirmed by observations of single cells. It follows therefore, that as the method we have described for obtaining synchronous cultures does not give complete synchrony, it is not possible to be more precise about the relationship between differentiation competence and the different phases of the cell cycle. Our experiments do suggest however, that there are large differences at different points in the cell cycle in the extent to which cells are able to initiate and complete differentiation, and that further consideration should be given to the nature of the transition from growth to differentiation in this organism.

\section{REFERENCES}

Ashworth, J. M. \& WatTs, D. J. (1970). Metabolism of the cellular slime mould Dictyostelium discoideum grown in axenic culture. Biochemical Journal 119, 175-182.

Blumenthal, L. K. \& ZahleR, S. A. (1962). Index for measurement of synchronization of cell population. Science 134, 724.

Chagla, A. H. \& Griffiths, A. J. (1978). Synchronous cultures of Acanthamoeba castellanii and their use in the study of encystation. Journal of General Microbiology 108, 39-43.

Herbert, D., Phipps, P. J. \& Strange, R. E. (1971). Chemical analysis of microbial cells. Methods in Microbiology 5B, 209-344.

Katz, E. R. \& Bourguignon, L. Y. W. (1974). The cell cycle and its relationship to aggregation in the cellular slime-mould Dictyostelium discoideum. Developmental Biology 36, 82-87.

Kissane, J. M. \& Robins, E. (1955). The fluorimetric measurement of DNA in animal tissues with special reference to the central nervous system. Journal of Biological Chemistry 233, 184-188.

Lloyd, D., John, L., Edwards, C. \& Chagla, A. H. (1975). Synchronous cultures of micro-organisms: large-scale preparation by continuous-flow size selection. Journal of General Microbiology 88, 153-158.
Loomis, W. F. (1969). Acetylglucosaminidase, an early enzyme in the development of Dictyostelium discoideum. Journal of Bacteriology 97, 1149-1154.

Loomis, W. F. (1970). Developmental regulation of $\alpha$ mannosidase in Dictyostelium discoideum. Journal of Bacteriology 103, 375-381.

LoomIs, W. F. (1971). Sensitivity of Dictyostelium discoideum to nucleic acid analogues. Experimental Cell Research 64, 484-486.

LoomIS, W. F. (1975). Dictyostelium discoideum: a Developmental System. New York \& London: Academic Press.

Mitchison, J. M. (1971). The Biology of the Cell Cycle. London: Cambridge University Press.

Sussman, R. R. \& Sussman, M. (1967). Cultivation of Dictyostelium discoideum in axenic medium. Biochemical and Biophysical Research Communications 29, 53-55.

WATTS, D. \& AsHWORTH, J. M. (1970). Growth of myxamoebae of the cellular slime-mould Dictyostelium discoideum in axenic culture. Biochemical Journal 119, 171-174.

Zada-Hames, I. M. \& Ashworth, J. M. (1978). The cell cycle during the vegetative stage of Dictyostelium discoideum and its response to temperature change. Journal of Cell Science 32, 1-20. 